\title{
Diazotrophic diversity, nifH gene expression and nitrogenase activity in a rice paddy field in Fujian, China
}

\author{
Lotta Mårtensson • Beatriz Díez • \\ Ingvild Wartiainen • Weiwen Zheng • \\ Rehab El-Shehawy • Ulla Rasmussen
}

Received: 21 October 2008 / Accepted: 17 March 2009

(C) Springer Science + Business Media B.V. 2009

\begin{abstract}
The diazotrophic communities in a rice paddy field were characterized by a molecular polyphasic approach including DNA/RNA-DGGE fingerprinting, real time RT-PCR analysis of nifH gene and the measurement of nitrogen fixation activities. The investigation was performed on a diurnal cycle and comparisons were made between bulk and rhizosphere / root soil as well as between fertilized / unfertilized soils. Real time RT-PCR showed no significant difference in the total quantity of nifH expression under the conditions investigated. The functional diversity and dynamics of the nifH gene expressing diazotroph community investigated using RT-PCR-DGGE revealed high diurnal variations, as well as variation between different soil types. Most of the sequence types recovered from the DGGE gels and clone libraries clustered within nifH Cluster I and III (65
\end{abstract}

Responsible Editor: Euan K. James.

L. Mårtensson · B. Díez · I. Wartiainen · R. El-Shehawy •

U. Rasmussen $(\bowtie)$

Department of Botany, Stockholm University,

SE-106 91 Stockholm, Sweden

e-mail: ulla.rasmussen@botan.su.se

W. Zheng

Biotechnology Center,

Fujian Academy of Agricultural Sciences,

Fuzhou, Fujian 350003, Peoples Republic of China different nifH sequences in total). Sequence types most similar to Azoarcus spp., Metylococcus spp., Rhizobium spp., Methylocystis spp., Desulfovibrio spp., Geobacter spp., Chlorobium spp., were abundant and indicate that these species may be responsible for the observed diurnal variation in the diazotrophic community structure in these rice field samples. Previously described diazotrophic cyanobacterial genera in rice fields, such as Nostoc and Cyanothece, were present in the samples but not detectable in RT-PCR assays.

Keywords Acetylene reduction assay $\cdot$ Microbial diversity $\cdot$ nifH gene activity . Real time RT-PCR - Rice paddy $\cdot$ RT-PCR-DGGE

\section{Introduction}

Intense research has been performed for many years on the application and utilization of diazotrophs as biofertilizers for rice production (Kennedy et al. 2004) and, although their positive effect on rice growth and productivity is well documented, we are far from a complete understanding and efficient exploitation of diazotrophic organisms as a natural nitrogen source. Several $\mathrm{N}_{2}$ fixing microorganisms have been isolated from rice fields (Park et al. 2005; Vaishampayan et al. 2001; Xie et al. 2003) and strains of Azotobacter, Clostridium, Azospirillum, Herbaspirillum, Burkholderia and Azoarcus, as well as cyanobacteria have, 
with positive results, been tested and found suitable for use as bio-fertilizers (Choudhury and Kennedy 2004). The identification of diazotrophs in rice paddy soil has so far, mainly been performed using cultivation-based analysis followed by morphologicaland/or molecular identification of individual isolates (Khan et al. 1994; Xie and Yokota 2005). However, only a limited number of microorganisms can be recovered from the soil by traditional cultivationbased techniques, resulting in underestimation of the amount and the significance of diazotrophs present in different soils (Garcia-Pichel et al. 2001; Smit et al. 2001).

In analysis of the indigenous diazotophic community in diverse environments, the nifH gene, encoding the dinitrogenase reductase part of the nitrogenase complex, is a commonly used marker for studying the diazotrophic assemblage and gene activity in different ecosystems (Zehr et al. 2003). Polymerase chain reaction (PCR) of the nifH gene combined with cloning and sequencing or denaturing gradient gel electrophoresis (DGGE) and sequencing gives information on the diazotrophic composition in an environment. Numerous PCR primers targeting the nifH genes have been designed with different range specificity, from "universal" covering different diazotropic taxa (Demba Diallo et al. 2008; Poly et al. 2001; Zehr et al. 1997; Wu et al. 2009), to genus and group specific (Huang et al. 1999; Olson et al. 1998). Recently, quantitative PCR (qPCR) has become a frequently used method to quantify specific genes or microbial groups in different environmental habitats (Lim et al. 2008; Novinscak et al. 2007). However, few studies have previously been performed on soil where qPCR is combined with reverse transcriptase (RT) PCR, enabling in vitro quantification of specific gene expression (Cook and Britt 2007; Jacobsen and Holben 2007) and qRT-PCR applied to the field emerge as a powerful tool for quantification of an active $\mathrm{N}_{2}$-fixing population within a complex community (Church et al. 2005) or to monitor diurnal gene expression (El-Shehawy et al. 2003; Zehr et al. 2007).

In the present study, we combined DGGE and cloning with real time RT-PCR and acetylene reduction activity (ARA) to identify the active diazotrophic community composition and to quantify nifH expression in rice paddy soil samples collected at a diurnal cycle.

\section{Materials and methods}

Soil characteristics and soil sampling

Soil samples were collected from two rice paddy fields each approximately $325 \mathrm{~m}^{2}$ in size, located in Yongtai $\left(25^{\circ} 39^{\prime} \mathrm{N} ; 119^{\circ} 12^{\prime} \mathrm{E}\right)$, Fujian province, South-East China. Since November 2003 one field was fertilized with $\mathrm{N}, \mathrm{P}, \mathrm{K}$ and urea, according to local custom and with two rice crops annually. The other field was fertilized only with $\mathrm{P}$ and $\mathrm{K}$ (referred to as F (fertilized) and UF (unfertilized) respectively). Fertilizer was added to the field two days before transplanting and 10, 45 and 75 days respectively after transplanting. Soil samples analyzed in this study were collected in May 2005, at which time the rice was in the active tillering phase. Composite soil samples were collected according to Nakatsu et al. (2000) and Smalla et al. (2001). The samples were collected in triplicate from bulk soil (B) $(0-1 \mathrm{~cm}$ depth) three times at 15:00, 20:00 and 04:00 in fertilized (F) and unfertilized (UF) soil. Concomitantly, rhizosphere/root samples (RH) were collected from 18 individual rice plants (three from each field at each sampling time). Excess soil (not in contact with roots) was manually removed and the roots and soil from 0-5 cm depth (of each plant) were sampled individually and mixed later during DNA/RNA extraction. In the field all samples were immediately submerged in liquid nitrogen and transported to the laboratory where they were kept in $-80^{\circ} \mathrm{C}$ until further processed. In July 2004 and May 2005, bulk soil was collected and analysed for chemical composition of the soil at the Soil and Fertilizer Institute of Fujian (Table 1). Temperature and light intensity at the sampling times were measured (Table 2).

RNA/DNA extraction and purification

Equal amounts of each of the three replicates from the rhizosphere/root samples were mixed in the laboratory, while the triplicates of the bulk soil were mixed directly in the field. Two grams from each mixed sample was used for crude RNA/DNA extraction according to the method described by Hurt et al. (2001). RNA was purified from crude RNA/DNA by the QIAGEN RNA/DNA mini-kit (Qiagen, Hilden, Germany) when used for RT-PCR-DGGE analysis, and further purified using the FastRNA Pro Soil 
Table 1 Chemical and trace element composition in the soil

\footnotetext{
${ }^{a}$ Between the first and second growth season

${ }^{\mathrm{b}}$ Middle of first (spring) growth season
}

\begin{tabular}{|c|c|c|c|c|c|c|c|c|c|}
\hline \multirow[b]{3}{*}{ Time and soil type } & \multirow[t]{3}{*}{ Organic matter $(\%)$} & \multirow{2}{*}{\multicolumn{3}{|c|}{ Total (\%) }} & \multirow{2}{*}{\multicolumn{3}{|c|}{$\frac{\text { Available }}{(\mathrm{mg} / \mathrm{kg})}$}} & \multirow{2}{*}{\multicolumn{2}{|c|}{$\frac{\text { Exchangeable }}{(\mathrm{mg} / \mathrm{kg})}$}} \\
\hline & & & & & & & & & \\
\hline & & $\mathrm{N}$ & $\mathrm{P}$ & $\mathrm{K}$ & $\mathrm{N}$ & $\mathrm{P}$ & $\mathrm{K}$ & $\mathrm{Ca}$ & $\mathrm{Mg}$ \\
\hline \multicolumn{10}{|l|}{ July $2004^{\mathrm{a}}$} \\
\hline Unfertilized & 3.61 & 0.21 & 0.03 & 1.47 & 299 & 5.2 & 37 & 674 & 68.4 \\
\hline Fertilized & 3.56 & 0.23 & 0.03 & 1.32 & 549 & 6.6 & 39 & 742 & 80.8 \\
\hline \multicolumn{10}{|l|}{ May $2005^{\mathrm{b}}$} \\
\hline Unfertilized & 2.78 & 0.18 & 0.03 & 1.91 & 184 & 10.8 & 41.5 & 442 & 81.1 \\
\hline Fertilized & 3.03 & 0.19 & 0.04 & 1.66 & 228 & 26.5 & 83.6 & 445 & 83.0 \\
\hline
\end{tabular}

Direct Kit (Promega) prior to qRT-PCR analysis. Additionally, all RNA samples were DNase treated (Qiagen) and tested for DNA contamination by PCR/ qPCR. The extracted DNA and RNA were stored at $-80^{\circ} \mathrm{C}$ until further analysis.

\section{Primer selection}

A variety of nifH PCR primers had previously been tested and optimized using DNA extracted from laboratory cultures of cyanobacteria, methanotrophs and rhizobia as well as environmental DNA from paddy soil (Wartiainen et al. 2008), and in this study RT-PCR-DGGE and quantitative nifH gene RT-PCR was performed with the primers PolF/PolR (Poly et al. 2001) and PolFI/AQER-GC30 (Wartiainen et al. 2008) as described in the following paragraphs.

\section{Quantitative nifH gene-RT-PCR (qRT-PCR)}

cDNA was synthesized from 200 ng RNA using the iScript cDNA synthesis Kit (BioRad, Hercules, CA, USA), according to the manufacturer's instructions, and stored at $-20^{\circ} \mathrm{C}$ until further processed. qPCR protocols were optimized for PCR efficiency using the universal diazotrophic primer pairs PolF and PolR (Poly et al. 2001). The optimal conditions for qPCR were found with $20 \mathrm{ng}$ cDNA as template $59^{\circ} \mathrm{C}$ annealing temperature and 40 cycles using iQ SYBR ${ }^{\circledR}$ Green qPCR Kit (Bio-Rad, Hercules, CA, USA) and according to the manufacturer's instruction. The quantitative PCR was carried out on a BioRad iCycler (Bio-Rad, Hercules, CA, USA). Following each run, a melt curve analysis step was performed to verify that primer-dimers were absent. To enable agarose gel electrophoresis, a $7 \mathrm{~min}$ final elongation step at $72^{\circ} \mathrm{C}$ was added at the end of the melt curve.

The relative cDNA quantities of nifH, and hence mRNA, were determined using serial dilutions of DNA (25 ng/ $\mu \mathrm{l}$ ) from Anabaena strain PCC 7120 as an external standard. Strong linear correlations (correlation coefficient $\left(\mathrm{r}^{2}\right)$ 1.000) were maintained between $\log$ values of template DNA and qPCR threshold cycles over the range of DNA concentrations examined. The efficiency of the real time PCR reactions were $86.8 \% \pm 0.25$, and the specificity of the reactions was confirmed by gel electrophoresis where all samples produced the predicted $361 \mathrm{bp}$ PCR fragment (data not shown). Finally, water was used instead of templates as a negative control to exclude that primers and PCR buffers used in this study were contaminated with nifH genes, as indicated by a study on commercial PCR primers and polymerases (Goto et al. 2005). Samples were analysed in three separate runs, with two replicates of each sample in each run.

Table 2 Temperature and light intensity at the sampling times

\begin{tabular}{llll}
\hline & \multicolumn{2}{l}{ Time } & \\
\cline { 2 - 4 } & $15: 00$ & $20: 00$ & $04: 00$ \\
\hline Temperature $\left({ }^{\circ} \mathrm{C}\right)$ & & & \\
Air & 34.0 & 25.0 & 24.0 \\
Water & 34.0 & 28.4 & 25.0 \\
Water surface & 32.5 & 28.2 & 25.0 \\
Light intensity (lux) & & & \\
Air & 21600 & 0 & 0 \\
Water surface & 14000 & 0 & 0 \\
\hline
\end{tabular}




\section{Diazotrophic nifH RT-PCR-DGGE}

A two-step RT-PCR protocol for nifH PCR amplifications and DGGE fingerprinting analysis were performed as previously described by Wartiainen et al. (2008). The RT reaction was set up according to the manufacturer's protocol (Eppendorf, Germany), with a reaction temperature of $42^{\circ} \mathrm{C}$ for 30 minutes. The cDNA was stored at $-20^{\circ} \mathrm{C}$ until further handling. A direct PCR approach with GC-clamp primers gave no products using the cDNA as template; therefore a nested PCR protocol was performed on the cDNA samples. In the first PCR reaction, a 370 base pair fragment of the nifH gene was amplified using the PCR primers PolF and PolR (Poly et al. 2001). The second PCR was performed with PCR primers PolFI/ AQER-GC30 and $1 \mu 1$ of the PCR products from first PCR as template. The PCR conditions were as previously described (Wartiainen et al. 2008). PCR amplifications were repeated three times and the different reactions were analyzed separately by denaturing gradient gel electrophoresis as described in Wartiainen et al. (2008). All possible DGGE bands were excised from the gels and submerged in $20 \mu \mathrm{l}$ DNAase/RNAase free $\mathrm{H}_{2} \mathrm{O}$ (ultraPURE, Gibco) and stored at $4^{\circ} \mathrm{C}$ over-night. $1 \mu \mathrm{l}$ from each excised band were reamplified using the same conditions as above and further tested by DGGE, for verification of band migration patterns. Bands with correct migrations patterns were further amplified and sequenced. $10 \mathrm{ng}$ of each template and $1.6 \mu \mathrm{M}$ primers were mixed and the samples were sequenced on an $\mathrm{ABI}$ 3130XL system (Applied Biosystems, Warrington, UK). The number/presence of DGGE bands were estimated using the QuantityOne software (Bio-Rad, Hercules, CA, USA).

\section{Cyanobacteria specific nifH PCR-DGGE}

Direct amplification of RNA with cyanobacterial specific PCR primers was not successful, therefore DGGE on DNA amplified with the cyanobacterial specific CNF (with a 40 bp GC clamp at the 5' end (Nübel et al. 1997)) and CNR primers (Olson et al. 1998) were performed as previously described (Díez et al. 2007). $1 \mu 1$ of DNA was used as template in 50 $\mu l$ reactions. The PCR conditions and thermal cycling used were as described above: except that the annealing temperature used was $50^{\circ} \mathrm{C}$. All samples were amplified in duplicates, pooled and concentrated to $25 \mu 1$ through evaporation at $37^{\circ} \mathrm{C}$ using increased air flow in the sample tubes prior to DGGE analysis. DGGE was performed as described above but on a $6 \%(\mathrm{w} / \mathrm{v})$ polyacrylamide gel submerged in $1 \mathrm{xTAE}$ buffer at $60^{\circ} \mathrm{C}$ with a linear 50 to $70 \%$ denaturant gradient and stained in SYBRGold prior to illumination. An aliquot of the eluted DNA was subjected to an additional PCR amplification using the same primers and sequenced on an ABI 3130XL system (Applied Biosystems, Warrington, UK). The number/ presence of DGGE bands were estimated using the QuantityOne software (Bio-Rad, Hercules, CA, USA).

Diazotrophic nifH clone libraries

Clone libraries were constructed from cDNA samples UFB04:00 and FB04:00. The PCR reaction was performed using the PolF/PolR primers (see above). Four PCR products from each sample were pooled and concentrated by ethanol precipitation prior to ligation into the prepared vector ( $\mathrm{pCR}$ 2.1) supplied with a TOPO TA cloning kit (Invitrogen) following the manufacturer's recommendations. Double-stranded plasmid DNA from selected clones (with correct insert size verified by PCR) was extracted using a QIAprep Spin miniprep kit (Qiagen, Halden, Germany) and sequenced on an ABI 3130XL system (Applied Biosystems, Warrington, UK).

Phylogenetic reconstructions

A consensus of each forward and reverse sequence pair was created using Pregap 4 and Gap 4 in the Staden package under windows. Partial nifH gene sequences obtained from excised DGGE bands and the RNA clone libraries were aligned in Bioedit version 7.0.4.1 (http://www.mbio.ncsu.edu/bioedit/ bioedit.html) using ClustalW. All sequences were subjected to BLASTN searches (www.ncbi.nlm.nih. gov/blast) (Altschul et al. 1997) and the closest relatives from GeneBank were included for phylogenetic analysis. Only sequences from published studies or culture collections were included. The neighborjoining method and Kimura two-parameter (K2P) were used in PAUP (version 4.0b10, Sinauer Associates Inc., Sunderland, MA) to estimate phylogenetic reconstructions. A total of 1000 bootstrap replicates 
were performed. The nifH gene sequences of several archaeal sequences were used as outgroup.

The sequences generated in this study have been deposited in the EMBL Nucleotide Sequence Database under accession numbers: AM946232-AM946263 (nifH-RT-PCR-DGGE bands A1-A32), AM946264AM946280 (nifH-PCR-DGGE bands B1-B16), and AM946281-AM946313 (nifH- RT-PCR clones).

\section{Acetylene Reduction Assay (ARA)}

Nitrogen fixation activity was measured using the acetylene reduction assay (ARA) (Hardy et al. 1968). Soil was sampled in triplicates from fertilized and unfertilized bulk- and rhizosphere soil (at 15:00, 20:00 and 04:00) and incubated individually with $10 \%$ acetylene for three hours. The assay included negative controls using $\mathrm{dH}_{2} \mathrm{O}$ incubated with $10 \%$ acetylene and rhizosphere soil sampled at 20:00 incubated without acetylene for three hours (both negative controls in three replicates). The measurements were done at Fujian Institute of Testing Technology, Fuzhou, China, using a gas chromatograph (Agilent Teqnologies $6890 \mathrm{~N}$ Network GC System) equipped with a GDX502 column and a flame ionisation detector.

Statistic analysis of the data

Two-factor ANOVA was performed to detect significant differences $(P<0.05)$ among data obtained from qRT-PCR and ARA.

\section{Results}

Soil characteristics

The soil texture was analysed in April and July 2004, and the soil was characterised as a silt loam (results not shown). The chemical analysis revealed small differences in total amount of nitrogen, phosphorus and potassium (NPK) between sampling times and soil types (Table 1). The amount of available $\mathrm{N}$ in the fertilized soil was reduced from $549 \mathrm{mg} / \mathrm{kg}$ in July 2004 to $228 \mathrm{mg} / \mathrm{kg}$ in May 2005. At the same time the amount of available $\mathrm{N}$ in unfertilized soil decreased from $299 \mathrm{mg} / \mathrm{kg}$ to $184 \mathrm{mg} / \mathrm{kg}$. The amount of available $\mathrm{P}$ and $\mathrm{K}$ increased whereas the trace elements $\mathrm{Ca}$ and $\mathrm{Mg}$ were not affected by the different management regimes (Table 1).

Quantitative nifH gene expression and $\mathrm{N}_{2}$-fixation activity

Results from the real time RT-PCR analysis revealed no significant differences between the samples (Fig. 1a) $(P<0.05)$, indicating that the community of the $\mathrm{N}_{2}$-fixing bacteria is stable in quantity in both fertilized and unfertilized bulk and rhizosphere/root soil and is not affected either by the type of soil or by the day/night cycle. Fig. 1a represents a reproducible pattern obtained from the real time PCR analysis. This result was further confirmed by measuring the total $\mathrm{N}_{2}$-fixation activity in the samples by the ARA. Also, the ARA activities showed no significant difference between samples $(P<0.05)$ (Fig. 1b).

Functional diversity and distribution of the active diazotrophic communities along a diurnal cycle

The RT-PCR-DGGE profiles of the nifH expressing communities from all samples are shown in Fig. 2a. High functional diversity was observed at different sampling times within both fertilized and unfertilized soil, as well as between rhizosphere/root and bulk soil.

Phylogenetic reconstructions of the excised nifH RT-PCR-DGGE bands (Fig. 2a) revealed similarities to phylotypes within nifH clusters I and III (Fig. 3). Moreover, all the sequences obtained from the RNA clone libraries were also affiliated within the same clusters. From a total of 32 RT-PCR-DGGE bands and 33 cDNA clones (20 clones from unfertilized bulk (04:00) and 13 clones from fertilized bulk (04:00)), 22 RT-PCR-DGGE bands and 20 cDNA clones belonged to nifH Cluster I (Fig. 3). Among those, 18 RT-PCR-DGGE bands and 19 cDNA clones were more closely related to different members of the proteobacteria family, from which 7 RTPCR-DGGE bands and at least 3 cDNA clones were most similar to members of $\beta$-proteobacteria, such as Azoarcus spp., Azospira oriza, Azotobacter spp., and Ideonella sp.. Four RT-PCR-DGGE bands and 4 cDNA clones were most similar to $\gamma$-proteobacteria such as Methylococcus, and 3 RT-PCR-DGGE bands and 4 cDNA clones most similar to rhizobial $\alpha$ - 
Fig. 1 nifH gene expression and activity along a diurnal cycle a Starting quantities (SQ) of nifH mRNA per reaction visualized as mean of duplicates with standard deviations b Nitrogenase activity per gram (dry weight) and hour, measured using the acetylene reduction assay (ARA), visualized as mean of triplicates with standard deviations. Abbreviations: Fertilized bulk (FB), fertilized rhizosphere/roots (FRH), unfertilized bulk (UFB), unfertilized rhizosphere/roots (UFRH) a

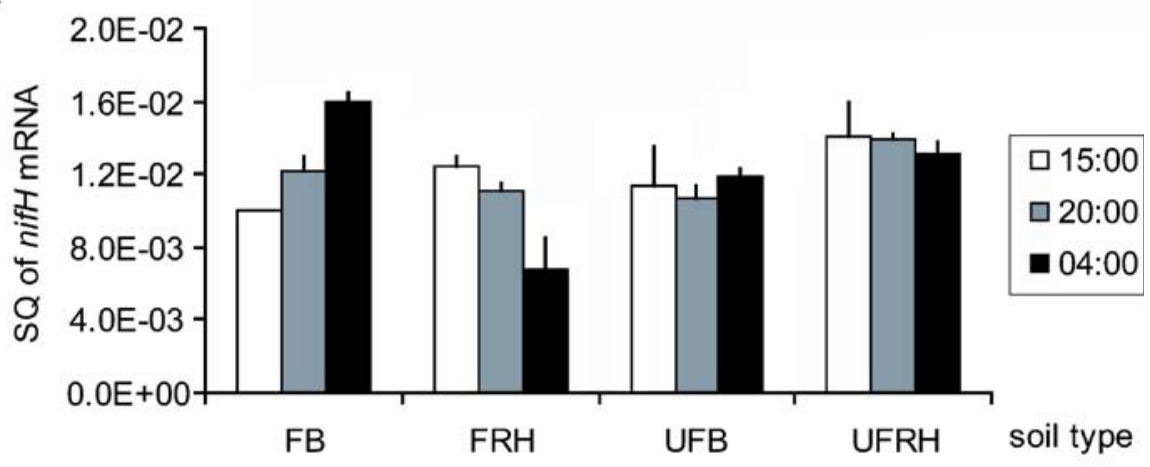

b

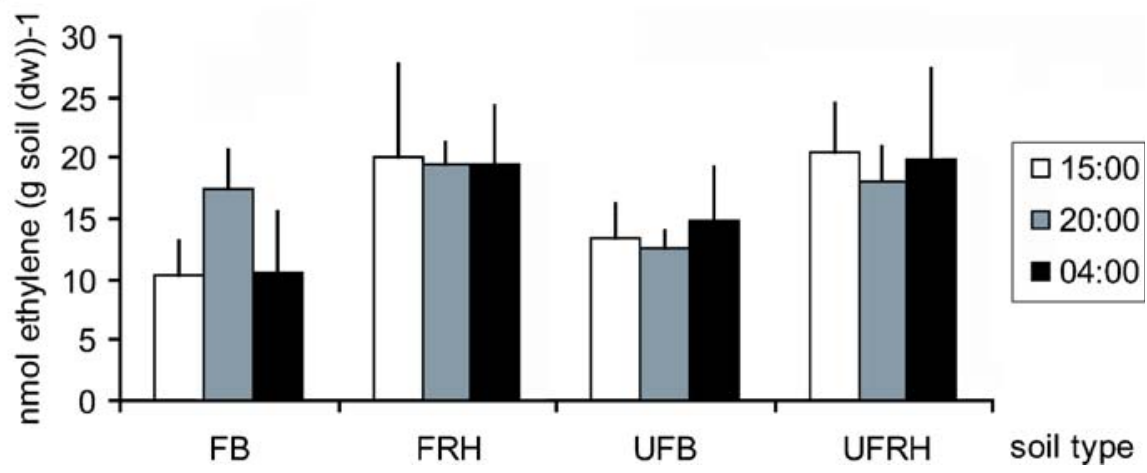

proteobacteria like Rhizobium or Methylocystis (Fig. 3). The remaining phylotypes were related to the heterogeneous clade including Firmicutes like Heliobacterium, $\delta$-proteobacteria like Geobacter and Actinobacteria like Frankia. In addition, 10 RTPCR-DGGE bands and 10 cDNA clones were closely related to the nifH Cluster III that includes nifH sequences from diverse anaerobic bacteria such as Clostridia (low $\mathrm{G}+\mathrm{C}$, gram positive), sulfate reducers such as Desulfobacter and Desulfovibrio ( $\delta$-proteobacteria) and the green sulfur-oxidizing bacterium Chlorobium (Chlorobia) (Fig. 3).

In general, the distribution of phylotypes between different soil types, or at different times within the soil types, appears to be indiscriminate. Twenty one of the 32 phylotypes were recovered from more than one DGGE profile (soil sample) (Fig. 2c). Many Firmicutes and $\delta$-proteobacteria phylotypes from cluster I and III of nifH gene were present both in fertilized and unfertilized samples (Fig. 2a, c; Fig. 3). None of the phylotypes recovered from DGGE bands or clone libraries were related to cyanobacteria. Furthermore, many of the sequences recovered from our DGGE bands and clone libraries showed similarities less than $92 \%$ when compared to the closest related sequences present in the NCBI GenBank database.

Diversity and distribution of the cyanobacterial community along a diurnal cycle

DNA-based PCR-DGGE was performed using cyanobacteria specific nifH primers $(\mathrm{CNF} / \mathrm{CNR}$ (Olson et al. 1998)). The result showed no major differences in the DNA-PCR-DGGE profile between the individual samples (Fig. 2b). The phylotypes identified were closely related to the heterocystous filamentous cyanobacteria genera Nostoc and Anabaena (DGGE bands B1, B6, B11, Fig. 2b), to the non-heterocystous unicellular genus Cyanothece (DGGE bands B5 and B9, Fig. 2b), which were relatively abundant in those samples (Fig. 2d), and to Dermocarpa sp. (DGGE band B10, Fig. 2b). The Cyanothece was also the most represented genus identified by $16 \mathrm{~S}$ rRNA-DGGE in the same samples (data not shown). In addition, phylotypes closely 
Fig. 2 nifH-DGGE

fingerprinting profiles on

the PCR amplified products

of RNA/DNA samples

extracted from rice paddy

along a diurnal cycle a

cDNA amplified in a

semi-nested approach using

general diazotroph nifH

primers PolF/PolR (Poly

et al. 2001) and PolFI/

AQER-GC30 (Wartiainen

et al. 2008) b DNA

amplified using

cyanobacteria specific nifH

primers CNF/CNR (Olson

et al. 1998). For clarification

the first four lanes have

been moved from the right

part of the gel using Adobe

Illustrator. Marks and

numbers indicate the

excised bands from which

sequences were determined.

c-d) Binary matrix indicat-

ing presence (black boxes)

or absence (empty boxes) of

bands in: $\mathbf{c}$ the PolF/PolR

DGGE gel and $\mathbf{d}$ the

CNF/CNR DGGE gel.

Numbers on the left

correspond to numbers

assigned to each band in the

DGGE. Bands that were

sequenced are numbered

accordingly with the

numbers on the DGGE.

Abbreviations: Fertilized

bulk (FB), fertilized

rhizosphere/roots (FRH),

unfertilized bulk (UFB),

unfertilized rhizosphere/

roots (UFRH) a
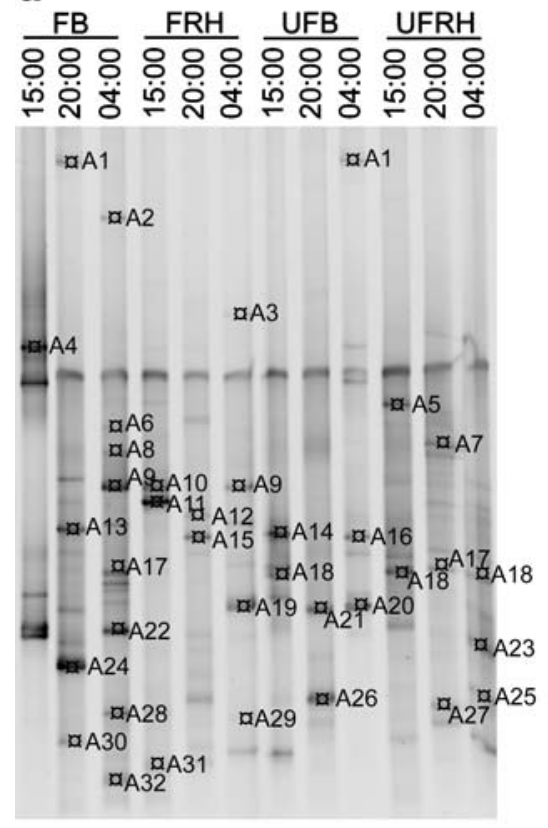

b
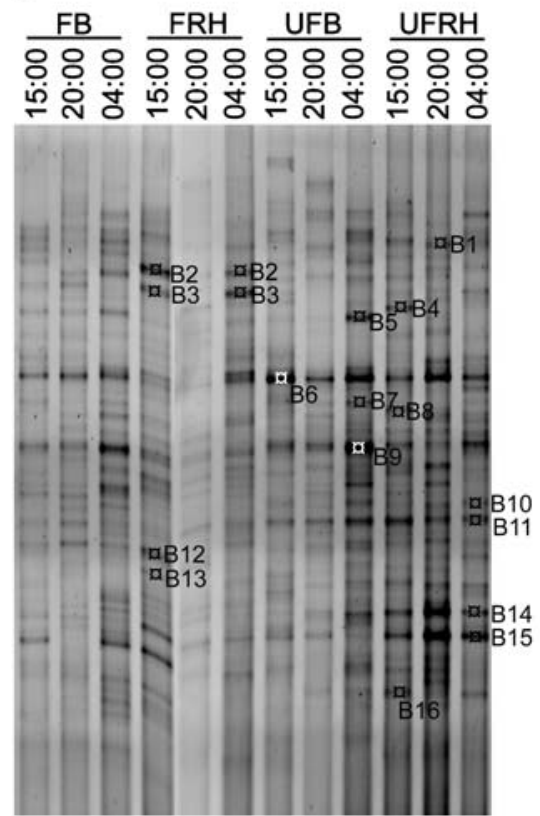

C

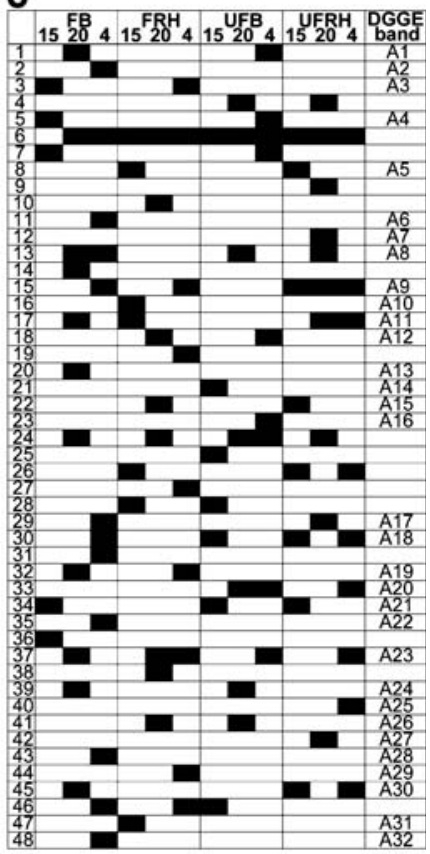

d

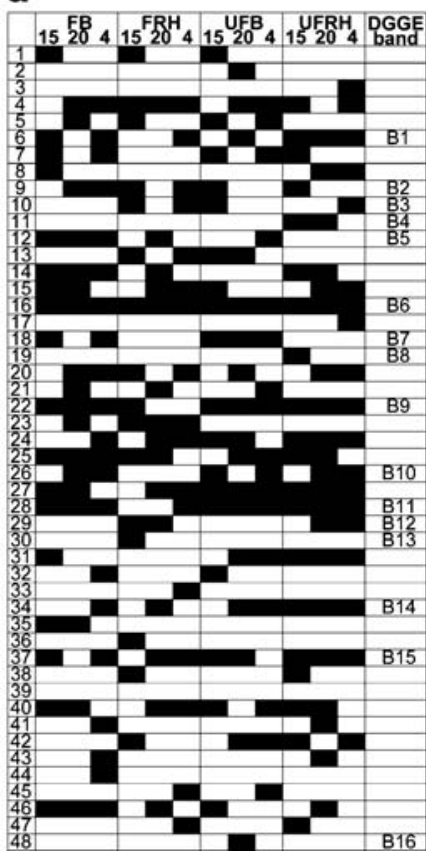

related to members of the Firmicutes from Cluster I (DGGE bands B12 and B13, Fig. 2b) as well as members of Cluster III (DGGE bands B3, B4, B7, B8, B14, B15, Fig. 2b) and one possibly related to
Cluster II (DGGE band B16, Fig. 2b) were identified (Fig. 3). Many of those phylotypes shared less than $90 \%$ similarity with sequences present in the NCBI GenBank database. 
Fig. 3 Estimated nifH phylogeny from the Paup analysis. Neighbour-joining tree based on 1000 bootstrap replicates using Kimura two parameter (K2P). Branch lengths are drawn proportional to the mean estimated change (scale bar is 0.05 substitutions per site). All sequences generated in this study are indicated in bold face.

DGGE band A1-A32 indicate RT-PCR-DGGE products amplified with general diazotroph primers PolF/PolR (Poly et al. 2001), DGGE band B1-B16 indicates PCR-DGGE products amplified with cyanobacteria specific primers CNF/CNR (Olson et al. 1998) and clone UFA1-UFE5 and FA1-FC6 indicates clones (amplified with PolF/PolR) from the RNA clone libraries unfertilized bulk (UF) and fertilized bulk (F) respectively. The tree was rooted on the branch to Methanocaldococcus jannaschii

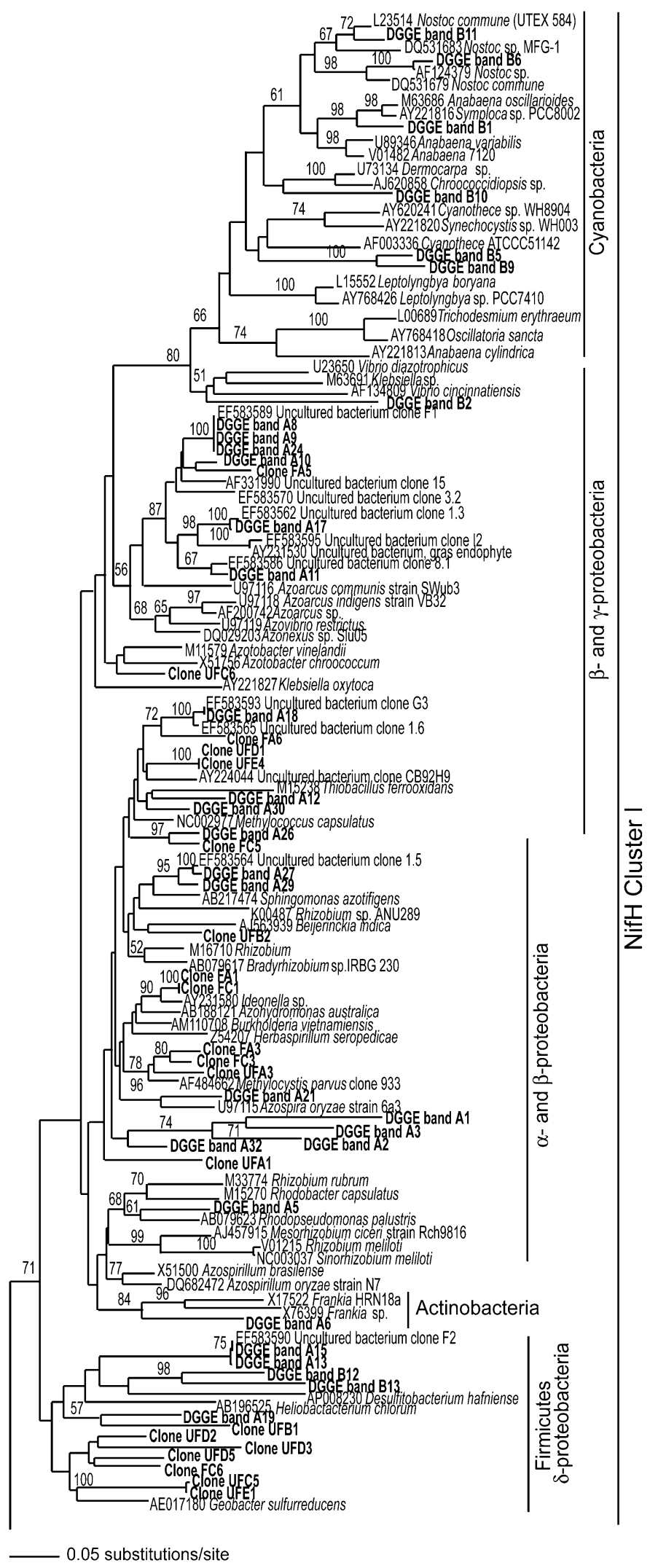


Fig. 3 (continued)

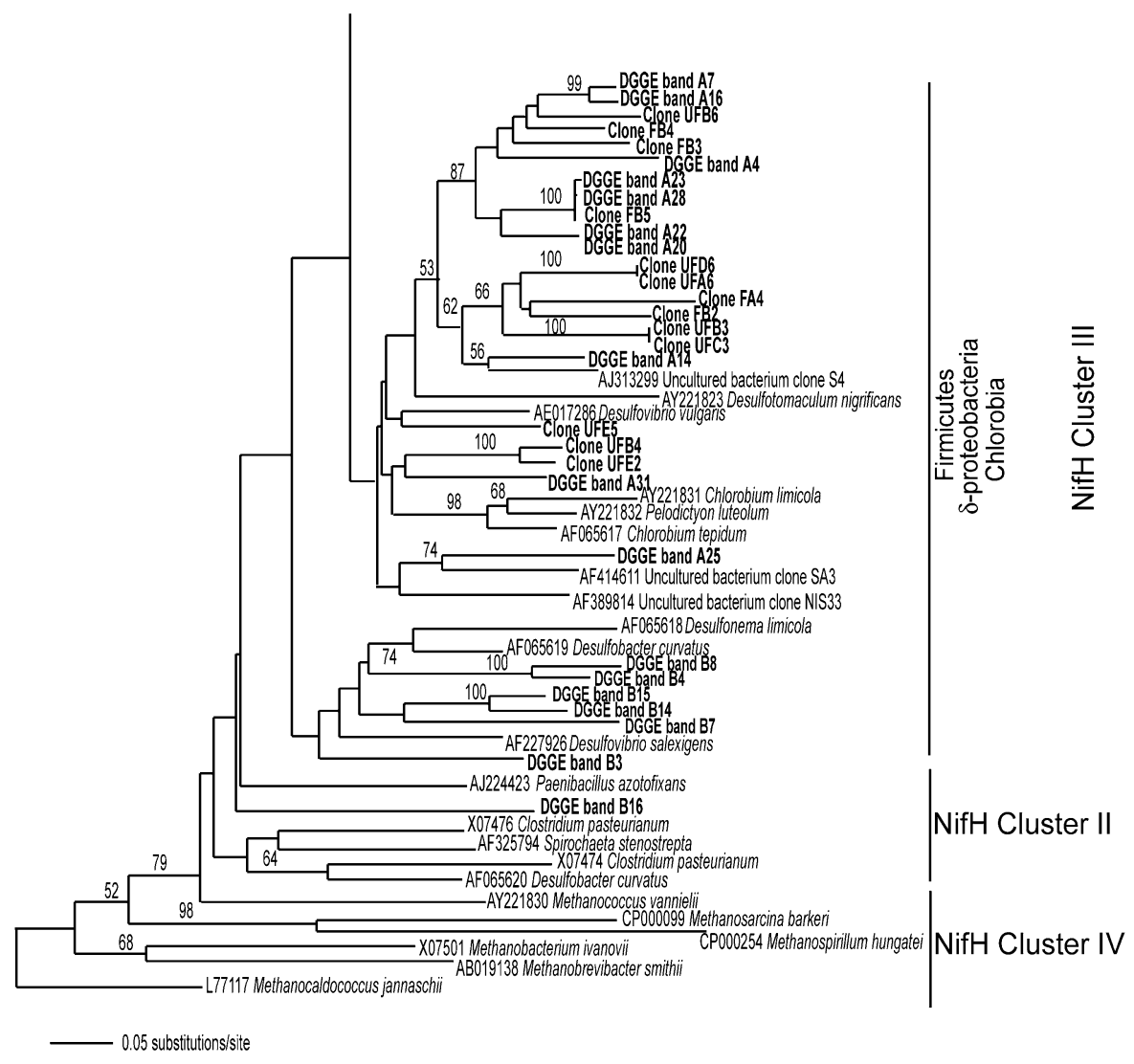

\section{Discussion}

In recent years, nifH has been one of the most important functional genes used when studying structural and functional diversity in numerous environments including diverse soil habitats (Bürgmann et al. 2003; Demba Diallo et al. 2008; Knauth et al. 2005; Poly et al. 2001; Wu et al. 2009). In the present study, the nifH gene was used as a molecular marker for studying the diazotrophic diversity and abundance in the rice paddy in an area with intensive farming practise, including two growth seasons a year.

The investigation of the nifH transcript using qRTPCR with the universal nifH diazotrophic primers showed that nifH gene expression together with nitrogenase activity measurements did not reveal any significant differences between the soil types or between the sampling times, indicating a stable $\mathrm{N}_{2}$ fixing community actively fixing nitrogen over the day/night cycle. These results are in accordance with the resent paper by Hsu and Buckley (2009) in which a relationship between $\mathrm{N}_{2}$-fixation rates and soil $\mathrm{N}$ or nitrate contents could not be found. Moreover, soil analysis performed from the two fields (Table 1) revealed that the amount of available nitrogen in unfertilized soil was only $44 \mathrm{mg} / \mathrm{kg}$ lower than in fertilized soil, and probably not low enough to be a discriminating factor. This might explain the absence of a significant difference in $\mathrm{N}_{2}$-fixation expression and activity between the fertilized and unfertilized soil types, and that the quantity of the nitrogen that is being provided to the fertilized soil is probably not affecting the $\mathrm{N}_{2}$-fixation activity of the microbial community. The unfertilized soil had been without nitrogen for 18 months, and it was therefore surprising to find such small differences in available nitrogen between the two different treatments. Although the concentration of available $\mathrm{P}$ and $\mathrm{K}$ was twice as high in fertilized than in unfertilized soil there was no observed effect on either the quantity or the activity of the diazotrophic activity in the samples. Thus, our results are not in accord with previous nitrogen fixation measurements from rice fields that showed diurnal 
patterns with peaks either at day (15:00) (Balandreau et al. 1974) or during the night (Abdel Wahab 1980), as well as seasonal variations (Quesada et al. 1998). This could be the result of differences in the diversity and/ or activity of the different $\mathrm{N}_{2}$-fixing communities present in our samples.

Our phylogenetic analysis showed that several phylotypes identified in the present study formed separate clusters where the closest related known cultured bacteria sequences in the database were members of the $\mathrm{N}_{2}$-fixing $\beta$-proteobacteria, e.g. genus Azoarcus. Azoarcus spp. has been described to be endophytically associated with the rhizosphere of Kallar grass (Letptochloa fusca (L.) Kunth) (Hurek et al. 2002), and associated with rice roots (Demba Diallo et al. 2008; Engelhard et al. 2000; Knauth et al. 2005; Wu et al. 2009) and might be an important active diazotroph in paddy fields (Wartiainen et al. 2008). Additionally, other sequences recovered in this study were closely related to known diazotrophic bacteria previously reported from the rice soil e.g. Methylococcus (Henckel et al. 1999; Mohanty et al. 2007) and Ideonella (Coelho et al. 2008; Lu et al. 2006).The findings indicate a significant importance of those organisms for the paddy ecosystem. However, the results are limited by the conditions used in the study, and PCR based methods on complex environments will underestimate the diversity, and may even underestimate dominating phylotypes. In a study of nif $H$ pools in roots of Oryza longistaminata, Demba Diallo et al. (2008) found that the Poly primers (Poly et al. 2001) was biased in amplification of nifH sequences from environmental samples, while the Zehr primers (Zehr and McReynolds 1989) detected a more complex nifH pool. As tested and described in previous work (Wartiainen et al. 2008), different nifH PCR primers were analyzed prior to this study, both on environmental samples and laboratory cultures of nitrogen fixing organisms such as rhizobia, methanotrophs and cyanobacteria. The only primers giving a single, correct sized PCR product from all test organisms and environmental samples was the primer pair described in this paper. Our results therefore indicate that the Poly (Poly et al. 2001) PCR primers give reliable information, and are able to amplify nifH sequences from a broad spectrum of diazotrophs from this ecosystem. Our results are in agreement with the findings by $\mathrm{Wu}$ et al. (2009) where the Poly primers successfully were applied to resolve a high diversity of proteobacteria associated with roots of modern rice cultivars.
In the present study, no phylotypes most similar to cyanobacteria were observed from the cDNA-DGGE analysis although cyanobacteria are known diazotrophs in the rice paddy (Khan et al. 1994; Song et al. 2005). In order to examine if a bias was generated by the nested PCR approach and/or from the DGGE analysis, two clone libraries from cDNA samples (UFB04:00 and FB04:00) were generated by direct amplification with the PolF/PolR primers. In accordance with the results from the RT-PCR-DGGE analysis, neither cyanobacterial phylotypes nor members of nifH phylogeny clusters II or IV were detected in the two selected clone libraries. However, all sequences recorded were closely related to and affiliated with the phylogenetic groups generated from the sequenced DGGE bands. This strongly indicates that no bias is generated with the nested PCR approach used for the DGGE fingerprinting analysis. To confirm that cyanobacteria were indeed present in the studied rice field the RNA and DNA were analyzed by cyanobacteria specific PCR primers (Olson et al. 1998). As PCR amplification of RNA using cyanobacteria specific primers was unsuccessful, DNA was amplified, analyzed by DGGE and sequencing. The phylogenetic analysis of these potential $\mathrm{N}_{2}$-fixing cyanobacterial populations showed a diverse composition and distribution of heterocystous and non-heterocystous as well as unicellular and filamentous cyanobacteria throughout the samples. Tentative phylogenetic affiliation related our cyanobacterial DGGE phylotypes to members of the Nostocales and the Chroococales. The unicellular $\mathrm{N}_{2}$-fixing cyanobacteria of the genus Cyanothece, which are known diazotrophs in paddy soils, were in this study relatively abundant and thus might be important nitrogen fixers in the ecosystem. Our findings indicate that cyanobacteria are present, but not detectable with the broad range PCR primers used in this study. The fact that we were unable to amplify cyanospecific nifH from RNA indicates that the cyanobacteria may be less active than heterotrophic diazotrops in this paddy field and that the input from the heterotrophic diazotrophic communities in the total nitrogen fixation budget might have been underestimated in previous studies. In accord, some recent studies indicate that the density and significance of cyanobacteria in rice paddy soil may have been overestimated when using culture- or microscopybased techniques (Ariosa et al. 2004). A more detailed study should be undertaken to investigate the nitrogen 
fixation input from cyanobacteria and other potential diazotrophic members of the community.

In summary, our analyses of the active diazotrophic community in the rice field revealed that a wide range of nitrogen fixing bacteria was actively fixing nitrogen, even under a normal fertilizer regime. Coupling reduced nitrogen fertilizing and biological nitrogen fixing activity to crop yield would be the next step in investigating the potential of using and increasing the biological nitrogen fixation in rice production.

Acknowledgments This work was supported by grants to UR from The Swedish International Development Cooperation Agency Department for Research Cooperation (Sida/SAREC) and The Swedish Research Link Programme. Grant from The Swedish Research Council (FORMAS) to RE is acknowledged. We also acknowledge the financial support from K. and A. Wallenberg Foundation. Dr. L. Zhou and Mr Z. Lin are acknowledged for help during the fieldwork, Ms C. Bin for help during fieldwork and DGGE experiments and Ms S. Vintila, Department of Botany, Stockholm University, for help with statistical analyses.

\section{References}

Abdel Wahab AM (1980) Nitrogen-fixing nonlegumes in Egypt. I. Nodulation and $\mathrm{N}_{2}\left(\mathrm{C}_{2} \mathrm{H}_{2}\right)$ fixation by Casuarina equisetifolia. Z Allg Mikrobiol 20:3-12

Altschul SF, Madden TL, Schaffer AA, Zhang J, Zhang Z, Miller W, Lipman DJ (1997) Gapped BLAST and PSI-BLAST: a new generation of protein database search programs. Nucleic Acids Res 25:3389-3402. doi:10.1093/nar/25.17.3389

Ariosa Y, Quesada A, Aburto J, Carrasco D, Carreres R, Leganes F, Fernandez Valiente E (2004) Epiphytic cyanobacteria on Chara vulgaris are the main contributors to $\mathrm{N}_{2}$ fixation in rice fields. Appl Environ Microbiol 70:5391-5397. doi:10.1128/AEM.70.9.5391-5397.2004

Balandreau JP, Millier CR, Dommergues YR (1974) Diurnal variations of nitrogenase activity in the field. Appl Microbiol 27:662-665

Bürgmann H, Widmer F, Sigler WV, Zeyer J (2003) mRNA extraction and reverse transcription-PCR protocol for detection of nifH gene expression by Azotobacter vinelandii in soil. Appl Environ Microbiol 69:1928-1935. doi:10.1128/AEM.69.4.1928-1935.2003

Choudhury ATMA, Kennedy IR (2004) Prospects and potentials for systems of biological nitrogen fixation in sustainable rice production. Biol Fertil Soils 39:219-227. doi:10.1007/s00374-003-0706-2

Church MJ, Jenkins BD, Karl DM, Zehr JP (2005) Vertical distributions of nitrogen-fixing phylotypes at Stn ALOHA in the oligotrophic North Pacific Ocean. Aquat Microb Ecol 38:3-14. doi:10.3354/ame038003

Coelho MR, de Vos M, Carneiro NP, Marriel IE, Paiva E, Seldin L (2008) Diversity of nifH gene pools in the rhizosphere of two cultivars of sorghum (Sorghum bicolor) treated with contrasting levels of nitrogen fertilizer. FEMS Microbiol Lett 279:15-22. doi:10.1111/ j.1574-6968.2007.00975.x

Cook KL, Britt JS (2007) Optimization of methods for detecting Mycobacterium avium subsp. paratuberculosis in environmental samples using quantitative, real-time PCR. J Microbiol Methods 69:154-160. doi:10.1016/j. mimet.2006.12.017

Demba Diallo M, Reinhold-Hurek B, Hurek T (2008) Evaluation of PCR primers for universal nifH gene targeting and for assessment of transcribed nifH pools in roots of Oryza longistaminata with and without low nitrogen input. FEMS Microbiol Ecol 65:220-228. doi:10.1111/j.15746941.2008.00545.x

Díez B, Bauer K, Bergman B (2007) Epilithic cyanobacterial communities of a marine tropical beach rock (Heron Island, Great Barrier Reef): diversity and diazotrophy. Appl Environ Microbiol 73:3656-3668. doi:10.1128/AEM.02067-06

El-Shehawy R, Lugomela C, Ernst A, Bergman B (2003) Diurnal expression of het $R$ and diazocyte development in the filamentous non-heterocystous cyanobacterium Trichodesmium erythraeum. Microbiology 149:1139-1146. doi:10.1099/mic.0.26170-0

Engelhard M, Hurek T, Reinhold-Hurek B (2000) Preferential occurrence of diazotrophic endophytes, Azoarcus spp., in wild rice species and land races of Oryza sativa in comparison with modern races. Environ Microbiol 2:131-141. doi:10.1046/j.1462-2920.2000.00078.x 2

Garcia-Pichel F, López-Cortés A, Nübel U (2001) Phylogenetic and morphological diversity of cyanobacteria in soil desert crusts from the Colorado plateau. Appl Environ Microbiol 67:1902-1910. doi:10.1128/AEM.67.4.1902-1910.2001

Goto M, Ando S, Hachisuka Y, Yoneyama T (2005) Contamination of diverse nifH and nifH-like DNA into commercial PCR primers. FEMS Microbiol Lett 246:33-38. doi:10.1016/j.femsle.2005.03.042

Hardy RWF, Holsten RD, Jackson EK, Burns RC (1968) The acetylene-ethylene assay for N2 fixation: Laboratory and field evaluation. Plant Physiol 43:1185-1207. doi:10.1104/ pp.43.8.1185

Henckel T, Friedrich M, Conrad R (1999) Molecular analyses of the methane-oxidizing microbial community in rice field soil by targeting the genes of the $16 \mathrm{~S}$ rRNA, particulate methane monooxygenase, and methanol dehydrogenase. Appl Environ Microbiol 65:1980-1990

Hsu S-F, Buckley DH (2009) Evidence for the functional significance of diazotroph community structure in soil. ISME J 3:124-136. doi:10.1038/ismej.2008.82

Huang TC, Lin RF, Chu MK, Chen HM (1999) Organization and expression of nitrogen-fixation genes in the aerobic nitrogen-fixing unicellular cyanobacterium Synechococcus sp. strain RF-1. Microbiology 145:743-753

Hurek T, Handley LL, Reinhold-Hurek B, Piche Y (2002) Azoarcus grass endophytes contribute fixed nitrogen to the plant in an unculturable state. Mol Plant Microbe Interact 15:233-242. doi:10.1094/MPMI.2002.15.3.233

Hurt RA, Qiu X, Wu L, Roh Y, Palumbo AV, Tiedje JM, Zhou J (2001) Simultaneous recovery of RNA and DNA from soils and sediments. Appl Environ Microbiol 67:44954503. doi:10.1128/AEM.67.10.4495-4503.2001 
Jacobsen CS, Holben WE (2007) Quantification of mRNA in Salmonella sp. seeded soil and chicken manure using magnetic capture hybridization RT-PCR. J Microbiol Methods 69:315-321. doi:10.1016/j.mimet.2007.02.001

Kennedy IR, Choudhury ATMA, Kecskes ML (2004) Nonsymbiotic bacterial diazotrophs in crop-farming systems: can their potential for plant growth promotion be better exploited? Soil Biol Biochem 36:1229-1244. doi:10.1016/ j.soilbio.2004.04.006

Khan ZUM, Befum T, Mandal R, Hossain MZ (1994) Cyanobacteria in rice soils. World J Microbiol Biotechnol 10:296-298. doi:10.1007/BF00414867

Knauth S, Hurek T, Brar D, Reinhold-Hurek B (2005) Influence of different Oryza cultivars on expression of nifH gene pools in roots of rice. Environ Microbiol 7:1725-1733. doi:10.1111/j.1462-2920.2005.00841.x

Lim J, Do H, Shin SG, Hwang S (2008) Primer and probe sets for group-specific quantification of the Genera Nitrosomonas and Nitrosospira using real-time PCR. Biotechnol Bioeng 99:1374-1383. doi:10.1002/bit.21715

Lu Y, Rosencrantz D, Liesack W, Conrad R (2006) Structure and activity of bacterial community inhabiting rice roots and the rhizosphere. Environ Microbiol 8:1351-1360. doi:10.1111/j.1462-2920.2006.01028.x

Mohanty SR, Bodelier PL, Conrad R (2007) Effect of temperature on composition of the methanotrophic community in rice field and forest soil. FEMS Microbiol Ecol 62:24-31. doi:10.1111/j.1574-6941.2007.00370.x

Nakatsu CH, Torsvik V, Ovreas L (2000) Soil community analysis using DGGE of $16 \mathrm{~S}$ rDNA polymerase chain reaction products. Soil Sci Soc Am J 64:1382-1388

Novinscak A, Surette C, Filion M (2007) Quantification of Salmonella spp. in composted biosolids using a TaqMan qPCR assay. J Microbiol Methods 70:119-126. doi:10.1016/j.mimet.2007.03.019

Nübel U, Garcia-Pichel F, Muyzer G (1997) PCR Primers to amplify $16 \mathrm{~S}$ rRNA genes from cyanobacteria. Appl Environ Microbiol 63:3327-3332

Olson JB, Steppe TF, Litaker RW, Paerl HW (1998) $\mathrm{N}_{2}$-fixing microbial consortia associated with the ice cover of Lake Bonney, Antarctica. Microb Ecol 36:231-238. doi:10.1007/s002489900110

Park M, Kim C, Yang J, Lee H, Shin W, Kim S, Sa T (2005) Isolation and characterization of diazotrophic growth promoting bacteria from rhizosphere of agricultural crops of Korea. Microbiol Res 160:127-133. doi:10.1016/j. micres.2004.10.003

Poly F, Monrozier LJ, Bally R (2001) Improvement in the RFLP procedure for studying the diversity of nifH genes in communities of nitrogen fixers in soil. Res Microbiol 152:95-103. doi:10.1016/S0923-2508(00)01172-4

Quesada A, Nieva M, Leganes F, Ucha A, Martin M, Prosperi C, Fernandez-Valiente E (1998) Acclimation of cyanobacterial communities in rice fields and response of nitroge- nase activity to light regime. Microb Ecol 35:147-155. doi:10.1007/s002489900069

Smalla K, Wieland G, Buchner A, Zock A, Parzy J, Kaiser S, Roskot N, Heuer H, Berg G (2001) Bulk and rhizosphere soil bacterial communities studied by denaturing gradient gel electrophoresis: plant-dependent enrichment and seasonal shifts revealed. Appl Environ Microbiol 67:47424751. doi:10.1128/AEM.67.10.4742-4751.2001

Smit E, Leeflang P, Gommans S, van den Broek J, van Mil S, Wernars K (2001) Diversity and seasonal fluctuations of the dominant members of the bacterial soil community in a wheat field as determined by cultivation and molecular methods. Appl Environ Microbiol 67:2284-2291. doi:10.1128/AEM.67.5.2284-2291.2001

Song T, Mårtensson L, Eriksson T, Zheng WW, Rasmussen U (2005) Biodiversity and seasonal variation of the cyanobacterial assemblage in a rice paddy field in Fujian, China. FEMS Microbiol Ecol 54:131-140. doi:10.1016/j.femsec. 2005.03.008

Vaishampayan A, Sinha RP, Häder D-P, Dey T, Gupta AK, Bhan U, Rao AL (2001) Cyanobacterial biofertilizers in rice agriculture. Bot Rev 67:453-516. doi:10.1007/BF02857893

Wartiainen I, Eriksson T, Zheng WW, Rasmussen U (2008) Variation in the active diazotrophic community in rice paddy-nifH PCR-DGGE analysis of rhizosphere and bulk soil. Appl Soil Ecol 39:65-75. doi:10.1016/j. apsoil.2007.11.008

Wu L, Ma K, Lu Y (2009) Prevalence of betaproteobacterial sequences in nifH gene pools associated with roots of modern rice cultivars. Microb Ecol 57:58-68. doi:10.1007/ s00248-008-9403-x

Xie CH, Yokota A (2005) Pleomorphomonas oryzae gen. nov., sp. nov., a nitrogen-fixing bacterium isolated from paddy soil of Oryza sativa. Int J Syst Evol Microbiol 55:12331237. doi:10.1099/ijs.0.63406-0

Xie GH, Cai MY, Tao GC, Steinberger Y (2003) Cultivable heterotrophic $\mathrm{N}_{2}$-fixing bacterial diversity in rice fields in the Yangtze River Plain. Biol Fertil Soils 37:29-38

Zehr JP, McReynolds LA (1989) Use of degenerate oligonucleotides for amplification of the nifH gene from the marine cyanobacterium Trichodesmium thiebautii. Appl Environ Microbiol 55:2522-2526

Zehr JP, Mellon MT, Hiorns WD (1997) Phylogeny of cyanobacterial nifH genes: evolutionary implications and potential applications to natural assemblages. Microbiology 143:1443-1450

Zehr JP, Jenkins BD, Short SM, Steward GF (2003) Nitrogenase gene diversity and microbial community structure: a cross-system comparison. Environ Microbiol 5:539-554. doi:10.1046/j.1462-2920.2003.00451.x

Zehr JP, Bench SR, Mondragon EA, McCarren J, DeLong EF (2007) Low genomic diversity in tropical oceanic N2-fixing cyanobacteria. Proc Natl Acad Sci USA 104:17807-17812. doi:10.1073/pnas.0701017104 